\title{
Escherichia coli Enteropatógena en Crías de Primate Aotus (Aotidae) con Diarrea en Cautiverio
}

\author{
Enteropathogenic Escherichia Coli IN Young Aotus (AOTIDAe) With DiarRHEa IN \\ CAPTIVITY
}

\author{
Nofre Sánchez P. ${ }^{1}$, Isabel Arias B. ${ }^{2}$, Hugo Gálvez C. ${ }^{1}$, Victoria Carranza ${ }^{3}$, \\ Arnulfo Romaina R. ${ }^{1}$
}

\section{Resumen}

La diarrea es el signo más frecuente de enfermedad gastrointestinal en crías de primates mantenidas en cautiverio. El estudio tuvo como objetivo aislar e identificar especies bacterianas presentes en crías de Aotus con diarrea, que son criadas en cautiverio con fines experimentales. Se tomaron muestras de heces mediante hisopado rectal a 78 ejemplares de 1 a 7 meses de edad de $A$. nancymae $(\mathrm{n}=65)$ y $A$. vociferans $(\mathrm{n}=13)$ con diarrea y a 29 ejemplares de 1 mes de edad, aparentemente sanos de $A$. nancymae $(\mathrm{n}=21)$ y A. vociferans $(\mathrm{n}=8)$, durante el periodo de 2002 a 2005. En el grupo control se identificó principalmente E. coli, además de Proteus vulgaris, $P$. mirabilis y Citrobacter freundii. Resultado similar fue registrado en el grupo con diarrea, además de Klebsiella oxitoca y Enterobacter aerogenes. Los serotipos de E. coli enteropatógena (EPEC) identificados en el grupo con diarrea fueron siete: O158, O142, O86, O125, O126, O55 y O111. Los resultados indican que las crías con diarrea tienen bacterias que corresponden a la flora intestinal normal, siendo E. coli la de mayor frecuencia.

Palabras clave: enterobacterias, EPEC, infantes, flora intestinal, mono nocturno, primates neotropicales

\section{Abstract}

Diarrhea is the most common sign of gastrointestinal disease in young primates kept in captivity. The study aimed to isolate and identify bacterial species present in young Aotus with diarrhoea. The animals were reared in captivity for experimental purposes. Faecal samples were collected using rectal swabs from 78 monkeys of 1 to 7 months old

${ }^{1}$ Centro de Reproducción y Conservación de Primates, Centro de Investigación IVITA, Universidad Nacional Mayor de San Marcos, Iquitos, Perú

${ }^{2}$ Laboratorio de Enteropatógenos, Instituto Nacional de Salud, Lima, Perú

${ }^{3}$ Laboratorio de Salud Pública, Iquitos, Perú

${ }^{4}$ E-mail:nofresp@hotmail.com

Recibido: 13 de enero de 2015

Aceptado para publicación: 11 de junio de 2015 
of $A$. nancymae $(\mathrm{n}=65)$ and $A$. vociferans $(\mathrm{n}=13)$ with diarrhoea, and 29 apparently healthy monkeys of 1 month old of $A$. nancymae $(\mathrm{n}=21)$ and $A$. vociferans $(\mathrm{n}=8)$ in the period 2002 to 2005 . In the healthy group was most commonly identified $E$. coli, followed by Proteus vulgaris, $P$. mirabilis and Citrobacter freundii. A similar result was obtained in the group with diarrhea, plus Klebsiella oxytoca and Enterobacter aerogenes. Serotypes of enteropathogenic E. coli (EPEC) identified in the group with diarrhea were seven: O158, O142, O86, O125, O126, O55, and O111. The results showed that young alpacas with diarrhea have bacteria corresponding to the normal intestinal flora, and the primary isolated bacterium was E. coli.

Key words: enterobacteria, EPEC, infants, intestinal flora, night monkey, neotropical primates

\section{INTRODUCCIÓN}

Aotus es un pequeño primate conocido en el Perú como «musmuqui» o «mono lechuza». Es el único género con hábitos nocturnos que se encuentra distribuido en Centro y Sudamérica. Asimismo, es uno de los primates más utilizados en investigación biomédica (Aiello, 2000).

El Centro de Reproducción y Conservación de Primates (CRCP), parte del Centro de Investigación IVITA, Universidad Nacional Mayor de San Marcos, viene reproduciendo Aotus nancymae y A. vociferans desde 1979. El manejo en cautiverio de animales de este género demuestra que la diarrea es el signo más usual de enfermedad gastrointestinal en crías (Sánchez et al., 2006). Asimismo, Carvalho et al. (2003) mencionan que la diarrea es también el principal problema en Callithrix sp mantenidos en cautiverio.

Los protocolos de necropsia (19982003) realizados en el CRCP en 66 crías de Aotus muestran la presencia de enteritis en el $40 \%$ de los casos, siendo la diarrea el signo clínico más común. Asimismo, la mayor frecuencia de muertes ocurrió en crías de uno a cuatro meses de edad (Sánchez et al., 2006). La supervivencia de las crías es un indicador que garantiza la continuidad del plantel reproductor de primates, de allí que el presente estudio tuvo como objetivo identificar las enterobacterias presentes en procesos diarreicos de crías Aotus manejados en el $\mathrm{CRCP}$, a fin de buscar una causa infecciosa que oriente el tratamiento.

\section{Materiales y Métodos}

El estudio fue realizado en el Centro de Reproducción y Conservación de Primates (CRCP) del Centro de Investigación IVITA, ubicado en el distrito de San Juan Bautista, Iquitos, Perú.

Se trabajó con 78 crías de Aotus nancymae $(\mathrm{n}=65)$ y $A$. vociferans $(\mathrm{n}=13)$ con signos clínicos de diarrea y con 29 crías de $A$. nancymae $(\mathrm{n}=21)$ y A. vociferans $(\mathrm{n}=8)$ aparentemente sanas, entre $2002 \mathrm{y}$ 2005. Las muestras se obtuvieron durante el registro de animales nacidos y durante el manejo rutinario de los animales. La categoría de cría en el CRCP comprende a ejemplares de un día hasta siete meses de edad. Debido a las características monógamas de las especies, en cada jaula se encontraba una pareja y su cría. Las jaulas de 1 x 1 x 2 m se encontraban en edificios de material noble de $8 \times 40 \times 3.5 \mathrm{~m}$, y en cada edificio se alojaban 62 parejas. El muestreo fue realizado en dos edificios de A. nancymae y en uno de $A$. vociferans. La alimentación que recibían era leche materna hasta aproximadamente el mes de edad y progresivamente se asociaba con el alimento balanceado ofrecido a sus padres. 
La limpieza de los ambientes se realizaba diariamente con agua a presión y detergente. La desinfección de los ambientes era mensual y se utilizaban desinfectantes comerciales. Todos los ejemplares eran desparasitados en el destete (7 meses de edad y $700 \mathrm{~g}$ de peso corporal) con ivermectina en forma subcutánea. Tratamientos antiparasitarios posteriores se efectuaban de acuerdo al calendario establecido en el CRCP.

Las diarreas fueron los primeros trastornos digestivos observados en las crías luego del nacimiento y fueron detectadas mediante observación directa de heces acuosas o mucoides en el piso de las jaulas, además de signos clínicos como pelaje sin brillo, ojos hundidos y periné sucio.

Para la colección de las muestras, las crías fueron retiradas de sus jaulas, utilizando una malla de nylon. Se hizo una limpieza previa de la zona perineal con algodón embebido en alcohol yodado. Se utilizó un hisopo estéril para tomar una muestra del recto. La muestra fue colocada en un tubo estéril y llevada al laboratorio para su procesamiento. Se descartó la presencia de parásitos gastrointestinales (helmintos y protozoarios) a través de un examen parasitológico por el método directo.

El cultivo, aislamiento e identificación de las enterobacterias se realizó a través de métodos convencionales (Koneman et al., 1983; Finegold y Martin, 1983; MINSA, 2005) en el laboratorio de la Estación del IVITA-Iquitos. Considerando que Escherichia coli es la principal bacteria aislada en casos de diarrea y que usualmente se encuentra asociada con cuadros infecciosos en primates, se realizó el serotipado de esta bacteria. Para esto, se utilizó una muestra representativa del grupo con diarrea, seleccionándose 50 muestras positivas a $E$. coli (44 de Aotus nancymae [17 machos y 27 hembras] de 11 a 144 días de edad y 6 de A. vociferans [ 1 macho y 5 hembras] de 30 a 49 días de edad para la evaluación de los serotipos presentes. El control de calidad de las cepas y posterior tipificación fue realizado en el Laboratorio Nacional de Referencia de Enteropatógenos del Instituto Nacional de Salud (Lima, Perú). El serotipado se realizó mediante la prueba de aglutinación en placa (Dedeiæ-Ljuboviæ et al., 2009; Lluque et al., 2010) utilizando antisuero polivalente de $E$. coli con anticuerpos somáticos de conejo (Laboratorio Denka Seiken, Tokio Japón)

\section{Resultados y Discusión}

Las crías de Aotus aparentemente sanas se mostraron dóciles a la manipulación, con ojos vivaces y pelaje aterciopelado, suave y brillante. La región del periné estaba rosada y limpia, las heces estaban formadas y eran de consistencia blanda, donde el color varió de mostaza a pardo, algunas veces mucoides y de olor no ofensivo. Se aisló mayormente E. coli, seguido por Proteus vulgaris, $P$. mirabilis y Citrobacter freundii (Cuadro 1). No se observaron helmintos ni protozoarios en los exámenes directos.

Las bacterias aisladas corresponden a la flora intestinal normal que se ha establecido en estas dos colonias de primates (Gozalo y Montoya, 1990; Weller, 1994; Sánchez et al., 2006). En humanos se ha estimado que la flora intestinal se establece dentro de las 24 horas del nacimiento, donde las bacterias que colonizan son propias del medio ambiente que los rodea, encontrándose principalmente Lactobacillus bifidus, pero pueden haber enterococos, bacterias coliformes $y$ estafilococos (Edwards y Parrett, 2002). Por otro lado, las bacterias que predominan en animales domésticos, como pollo, vaca, oveja, perro, gato y caballo, son coliformes, Lactobacillus y Eubacterium (Dreumel y Barker, 1990; Sørum y Sunde, 2001).

En el Cuadro 2 se presentan las bacterias aisladas en las crías con diarrea, donde fueron identificadas todas las bacterias del grupo control, además de Klebsiella y 
Cuadro 1. Enterobacterias aisladas de muestras fecales de crías Aotus de un mes de edad, aparentemente sanas, criadas en cautiverio en el Centro de Reproducción y Conservación de Primates (CRCP) del Centro de Investigación IVITA, Iquitos, Perú (2002-2005)

\begin{tabular}{lrrrr}
\hline \multirow{2}{*}{ Bacterias } & \multicolumn{2}{c}{$\begin{array}{c}\text { Aotus nancymae } \\
(\mathrm{n}=21)\end{array}$} & \multicolumn{2}{c}{$\begin{array}{c}\text { Aotus vociferans } \\
(\mathrm{n}=8)\end{array}$} \\
\cline { 2 - 5 } & $\mathrm{n}$ & $\%$ & $\mathrm{n}$ & $\%$ \\
\hline Escherichia coli & 10 & 47.6 & 5 & 63.5 \\
Proteus vulgaris + E. coli & 6 & 28.6 & 3 & 37.5 \\
Citrobacter freundii & 3 & 14.3 & 0 & 0 \\
Proteus mirabilis + E. coli & 2 & 9.5 & 0 & 0 \\
\hline Total & 21 & 100.0 & 8 & 100.0 \\
\hline
\end{tabular}

Cuadro 2. Enterobacterias aisladas de muestras fecales de crías Aotus con presencia de un cuadro diarreico y criadas en cautiverio en el Centro de Reproducción y Conservación de Primates (CRCP) del Centro de Investigación IVITA, Iquitos, Perú (2002-2005)

\begin{tabular}{lrrrr}
\hline \multirow{2}{*}{ Bacterias } & \multicolumn{2}{c}{$\begin{array}{c}\text { Aotus nancymae } \\
(\mathrm{n}=65)\end{array}$} & \multicolumn{2}{c}{ Aotus vociferans } \\
& $\mathrm{n}$ & $\%$ & $\mathrm{n}=13)$ & $\%$ \\
\cline { 2 - 5 } & 56 & 86.2 & 8 & 61.5 \\
\hline Escherichia coli & 3 & 4.6 & 2 & 15.4 \\
Proteus vulgaris & 2 & 3.1 & 2 & 15.4 \\
Proteus vulgaris + E. coli & 2 & 3.1 & 0 & 0 \\
Klebsiella oxitoca & 1 & 1.5 & 1 & 7.7 \\
Citrobacter freundii & 1 & 1.5 & 0 & 0 \\
Enterobacter aerogenes & 65 & 100.0 & 13 & 100.0 \\
\hline Total & & & & \\
\hline
\end{tabular}

Enterobacter. Quistes de un protozoario fueron observados en poca cantidad en cinco muestras de heces.

En ambas especies, las diarreas se presentaron principalmente a los dos meses de edad, con un rango de presentación entre el primer y cuarto mes de edad. Un ejemplar murió por una severa deshidratación a consecuencia de la diarrea. En la necropsia se observó el intestino severamente afectado, con la pared delgada y traslúcida por la pérdida de mucosa; asimismo, los ganglios mesentéricos estaban aumentados de tamaño y de color oscuro.

La consistencia de las heces varió de acuosa a mucoide, con colores amarillento a verdoso, y olor no ofensivo. Las crías presentaron mayormente un halo húmedo alrededor del esfínter anal, producto de las diarreas. 
Cuadro 3. Serotipos de Escherichia coli enteropatógena en crías de Aotus con signos clínicos de diarrea

\begin{tabular}{ccc}
\hline $\begin{array}{c}\text { Serotipos } \\
\text { de E. coli }\end{array}$ & $\begin{array}{c}\text { Aotus } \\
\text { nancymae } \\
(\mathrm{n}=44)\end{array}$ & $\begin{array}{c}\text { Aotus } \\
\text { vociferans } \\
(\mathrm{n}=6)\end{array}$ \\
\hline O158 & 3 & 1 \\
O142 & 3 & 1 \\
O86 & 2 & 0 \\
O125 & 1 & 0 \\
O126 & 0 & 1 \\
O55 & 1 & 0 \\
O111 & 1 & 0 \\
\hline Total & 11 & 3 \\
\hline
\end{tabular}

Los resultados coinciden con las observaciones realizadas por Zwadyk (1997) quien indica que E. coli, Citrobacter freundii, Proteus vulgaris y $P$. mirabilis son bacterias naturales del tracto intestinal. Estos son microorganismos oportunistas que pueden infectar cualquier sitio del organismo cuando encuentran un huésped alterado (Burke et al., 2010). En primates, Proteus es una bacteria asociada a gastroenteritis hemorrágica, por lo que no se le puede considerar como bacteria contaminante. Otros investigadores coinciden que Klebsiella pneumoniae es la bacteria oportunista más importante en primates no humanos (Carlton y Hunt, 1978; Gozalo y Montoya, 1990) y altamente patógena (Weller, 1994).

Weller (1994) indica que factores dietéticos aparecen como la causa primaria de la diarrea, lo cual coincide con la experiencia en el manejo de Aotus en el CRCP, donde las crías empiezan a probar alimento sólido a partir del mes de edad y este cambio de dieta podría estar asociado al trastorno.

La elevada frecuencia de $E$. coli en las muestras de ambos grupos (90 y $87 \%$ en el grupo control y con diarrea, respectivamen- te), tiene una clara relación con el reporte de McClure et al. (1978), quienes observaron cuadros clínicos y dos muertes de infantes de antropoides como consecuencia de una infección por $E$. coli enteropatógena (EPEC). Asimismo, Mansfield et al. (2001) reportaron colitis ulcerativa en Saguinus oedipus causada por EPEC.

Los serotipos EPEC identificados en el grupo con diarrea fueron siete, los cuales se describen en el Cuadro 3. Se identificó un serotipo por muestra. Los resultados obtenidos coinciden con algunos serotipos que la OMS establece como importantes para la salud pública.

En 1987, la Organización Mundial de la Salud reconoció 12 serotipos O de la EPEC: O26, O55, O86, O111, O114, O119, O125, O126, O127, O128, O 142 y O158. Los serotipos encontrados en el presente estudio han sido reportados por otros investigadores asociados a brotes de diarrea en niños, específicamente en lactantes de guarderías y hospitales de Reino Unido, Canadá e Israel (Zwadyk, 1997). Los brotes importantes de diarrea causada por EPEC han desaparecido en la mayoría de países desarrollados, pero se mantienen como causa importante de diarreas fatales en niños de países en desarrollo, focalizándose en grupos sociales de bajo nivel económico; así, O72 y O42 han sido reportados en cuadros de diarreas en niños en Brasil (Ghilardi et al., 2003), O55, O111 y O119 en Uruguay (Trabulsi et al., 2002; Blanco et al., 2006) y $\mathrm{O} 86$ y O44 en Bosnia y Herzegovina (Dediec-Ljubovic et al., 2009).

Carvalho et al. (2003) refieren que los serotipos de EPEC han estado asociados con diarrea en infantes y mortalidad en humanos en países en desarrollo y que serotipos EPEC similares identificados en Callitrichidos pueden ser patógenos importantes en primates. Asimismo, este autor comparó, mediante técnicas moleculares, cepas de EPEC procedentes de Callitrix jacchus, C. penicillata y Saguinus fuscicollis sanos y enfermos con cepas obtenidas de niños con diarrea en Bra- 
sil, concluyendo que existe una fuerte correlación genética entre ambos serotipos. Esto indica que los serotipos identificados en crías de primates con diarrea tienen potencial zoonótico.

\section{Conclusiones}

- La bacteria aislada de mayor frecuencia en crías con diarrea fue Escherichia coli, seguido de Proteus vulgaris, Klebsiella oxitoca, Citrobacter freundii y Enterobacter aerogenes, siendo estas bacterias parte de la flora intestinal normal del primate.

- Los serotipos de E. coli enteropatógena identificados fueron: O158, O142, O86, O125, O126, O55 y O111, los cuales tienen relevancia por su potencial zoonótico.

\section{Agradecimiento}

Los autores agradecen la colaboración del personal técnico del CRCP Deciderio Mariche, Asunción López Maca, Luiz A. Guzmán Mariche y Alfonzo Cahuaza López.

\section{Literatura Citada}

1. Aiello SE. 2000. Animales exóticos y de laboratorio. En: Manual Merck de Veterinaria. $5^{\text {a }}$ Ed. España: Océano. 380 p.

2. Blanco M, Blanco EJ, Dhabi G, Mora A, Alonso M, Varela G, Pilar M, Schelotto F, González E. Blanco J. 2006. Typing of intimin (eae) genes from enteropathogenic Escherichia coli (EPEC) isolated from children with diarrhoea in Montevideo, Uruguay: identification of two novel intimin variants (muB and xiR/beta2B). J Med Microbiol 55: 1165-1174.

3. Burke R, West M, Erwin-Cohen R, Selbly E, Fisher D, Twenhafel N. 2010. Alterations in cytokines and effects of dexamethasona immunosuppression during subclinical infections of invasive Klebsiella pneumoniae with hypermucoviscosity phenotype in Rhesus (Macaca mulatta) and cynomolgus (Macaca fasciculares) macaques. Comp Med 60(1): 62-70.

4. Carlton WW, Hunt RD. 1978. Pathology of laboratory animals. Bacterial diseases. Vol II. New York: Springer Verlac. $1411 \mathrm{p}$.

5. Carvalho VM, Gyles CL Ziebell K, Ribeiro MA, Catao-DiazJL, Sinhorini IL, Otman J, et al. 2003. Characterization of monkey enteropatho-genic Escherichia coli (EPEC) and human typical and atypical EPEC serotype isolates from neotropical nonhuman primates. J Clin Microbiol 41: 1225-1234.

6. Carvalho VM, Irino K, Onuma D, Pestana de Castro AF. 2007. Random amplification of polimorphic DNA reveals relationships among enteropathogenic Escherichia coli isolated from nonhuman primates and humans. Braz J Med Biol Res 40: 237-241.

7. Dedeia-Ljuboviae A, Hukiae M, Bekiae D, Zvizdice A. 2009. Frequency and distribution of diarrhoeagenic Escherichia coli strains isolated form pediatric patients with diarrhea in Bosnia and Herzegovina. Bosnian J Basic Med Sci 9: 148-155.

8. Dreumel VA, Barker KI. 1990. El sistema digestivo. En: Patología de los animales domésticos. Vol 2. $3^{\text {a }}$ ed. Montevideo: Hemisferio Sur. p 67-84.

9. Edwards CA, Parrett AM. 2002. Intestinal flora during the first months of life: new perspectives. Brit J Nutr 88(Suppl 1): S11-S18.

10. Finegold MS, Martín JW. 1983. Diagnóstico microbiológico. Buenos Aires: Médica Panamericana. $670 \mathrm{p}$.

11. Gozalo A, Montoya E. 1990. Mortality causes of owl monkey (Aotus nancymaes and Aotus vociferans) in captivity. J Med Primatol 19: 69-72.

12. Ghilardi AC, Gomez TA, Elias WP, Trabulsi LR. 2003. Virulence factors of Escherichia coli strains belonging to serogroups O127 and O142. Epidemiol Infec 131: 815-821. 
13. Koneman WE, Allen DS, Dowell RV, Sommers MH. 1983. Diagnóstico microbiológico. Buenos Aires: Médica Panamericana. $533 \mathrm{p}$.

14. Lluque A, Mercado E, Riveros M, Alvarado L, Carlos E, Calichon A, et al. 2010. Comparación entre el diagnóstico serológico y el diagnóstico por Reacción en Cadena de la Polimerasa (PCR) para Escherichia coli enteropatogénica (EPEC). Rev Gastroenterol Perú 30: 121-125.

15. Mansfield KG, Kuel-Chin L, Xia D, Newman JB, Shauer DB, Mackey J, Lackner AA, et al. 2001. Enteropathogenic Escherichia coli and ulcerative colitis in cotton-top tamarins (Saguinus eodipus). J Infect Dis 184: 803-807. doi: $10.1086 / 322990$

16. McClure HM, Chapman WL, Hooper BE, Smith FG, Fletcher OJ. 1978. The digestive system. In: Pathology of laboratory animals. Vol. I. New York: Springer. p 175-192.

17. [MINSA] Ministerio de Salud del Perú. 2005. Manual de procedimientos bacteriológicos en infecciones intrahospitalarias. Instituto Nacional de Salud Perú. Serie de Normas Técnicas N. ${ }^{\circ} 28$. $106 \mathrm{p}$.

18. Sánchez N, Gálvez H, Montoya E, Gozalo A. 2006. Mortalidad en crías de Aotus sp (Primates: Cebidae) en cautiverio: una limitante para estudios biomédicos con modelos animales. Rev Peru Med Exp Salud Públ 23: 221-224.

19. Sørum H, Sunde M. 2001. Resistance to antibiotics in the normal flora of animals. Vet Res 32: 227-241.

20. Trabulsi LR, Keller R, Tardelli Gomes TA. 2002. Typical and atypical enteropathogenic Escherichia coli. Emerg Infect Dis 8: 508-513.

21. Weller RE. 1994. Infectious and noninfectious diseases of owl monkeys. In: Aotus: the owl monkey. California: Academic Press. p 181-199.

22. Zwadyk P. 1997. Enterobacteriaceae oportunistas. En: Zinsser Microbiología. $20^{\circ}$ ed. Argentina: Médica Panamericana. p 744-758. 